\title{
Hyperfractionated Accelerated Radiation Delivered with Integrated Neck Surgery
}

National Cancer Institute

\section{Source}

National Cancer Institute. Hyperfractionated Accelerated Radiation Delivered with

Integrated Neck Surgery. NCI Thesaurus. Code C142774.

The integration of planned neck surgery subsequent to the delivery of hyperfractionated accelerated radiation. 